\title{
BMJ Open Job stress and burnout in hospital employees: comparisons of different medical professions in a regional hospital in Taiwan
}

\author{
Li-Ping Chou, ${ }^{1,2}$ Chung-Yi Li, ${ }^{2,3}$ Susan $\mathrm{C} \mathrm{Hu}^{2}$
}

To cite: Chou L-P, Li C-Y, Hu SC. Job stress and burnout in hospital employees: comparisons of different medical professions in a regional hospital in Taiwan. BMJ Open 2014;4: e004185. doi:10.1136/ bmjopen-2013-004185

- Prepublication history for this paper is available online. To view these files please visit the journal online (http://dx.doi.org/10.1136/ bmjopen-2013-004185).

Received 6 October 2013 Revised 24 December 2013 Accepted 14 January 2014

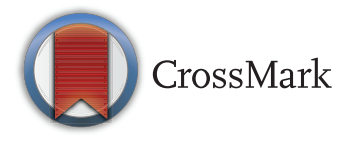

${ }^{1}$ Division of Cardiology, Department of Medicine, Sin-Lau Hospital, Tainan, Taiwan

${ }^{2}$ Department of Public Health, College of Medicine, National Cheng Kung University, Tainan, Taiwan ${ }^{3}$ Department of Public Health, China Medical University, Taichung, Taiwan

Correspondence to Dr Susan C Hu; shuhu@mail. ncku.edu.tw

\section{ABSTRACT}

Objectives: To explore the prevalence and associated factors of burnout among five different medical professions in a regional teaching hospital.

Design: Cross-sectional study.

Setting: Hospital-based survey.

Participants: A total of 1329 medical professionals were recruited in a regional hospital with a response rate of $89 \%$. These voluntary participants included 101 physicians, 68 physician assistants, 570 nurses, 216 medical technicians and 374 administrative staff.

Primary and secondary outcome measures: Demographic data included gender, age, level of education and marital status, and work situations, such as position, work hours and work shifts, were obtained from an electronic questionnaire. Job strain and burnout were measured by two validated questionnaires, the Chinese version of the Job Content Questionnaire and the Copenhagen Burnout Inventory.

Results: Among the five medical professions, the prevalence of high work-related burnout from highest to lowest was nurses $(66 \%)$, physician assistants $(61.8 \%)$, physicians ( $38.6 \%)$, administrative staff $(36.1 \%)$ and medical technicians $(31.9 \%)$, respectively. Hierarchical regression analysis indicated that job strain, overcommitment and low social support explained the most variance $(32.6 \%)$ of burnout.

Conclusions: Physician assistant is an emerging high burnout group; its severity is similar to that of nurses and far more than that of physicians, administrative staff and medical technicians. These findings may contribute to the development of feasible strategies to reduce the stress which results in the burnout currently plaguing most hospitals in Taiwan.

\section{INTRODUCTION}

Medical practice is stressful. This is because medical personnel must respond to the needs of patients and families very quickly. However, medical knowledge and procedures usually include limitations and uncertainties. Any medical errors or mistakes may be costly, harmful to a patient's life and sometimes

\section{Strengths and limitations of this study}

- This is the first report to compare burnout conditions among most of the medical professions in a hospital setting; the large sample size and high response rate also strengthen the power of this study.

- Participants were from a single regional hospital; therefore, it is not possible to generalise the conclusions for medical professions across the whole of Taiwan's hospitals.

- Stressful life events and work-family conflicts, which may affect the outcome of burnout, as found in other studies, were not examined in this research.

- This study was conducted with a cross-sectional design; therefore, the limitation of weak causal inference is inherent.

irreversible. Moreover, night work, shift work and long work hours are also very common in medical professions.

A great deal of research has indicated that long-term exposure to job-related stress can lead to burnout. ${ }^{12}$ Freudenberger ${ }^{3}$ first used the term 'burnout' to describe the gradual emotional depletion, loss of motivation and reduced commitment among volunteers who worked for a drug misuser. After three decades, burnout has been defined as a psychological syndrome that may emerge when employees are exposed to a stressful working environment with high job demands and low resources. $^{4} 5$ At the outset, burnout was reported most predominantly among human service workers. In the modern society, job stress and burnout are important issues for healthcare professionals. Burnout not only endangers their health and well-being, but also is associated with higher medical errors and suboptimal quality of care. ${ }^{6-8}$

There has been a lot of research on burnout in nurses, presumably because of 
the intense nature of their contact with patients or clients. Gray-Toft and Anderson ${ }^{9}$ have indicated seven fundamental stressors among nursing staff. These included the death and suffering of patients, conflict with physicians, inadequate training, lack of social support, conflicts with other nurses, excessive workload and uncertainty about a treatment given. Similarly, a high prevalence of burnout among physicians has also been reported from various countries, for different specialists. $^{10-13}$ The potential sources of physician burnout are time pressure, delayed gratification, limited control and a loss of autonomy, conflict between career and family, feelings of isolation, as well as research and teaching activities. ${ }^{8} 14$

Although many studies have discussed the stress and burnout situation for physicians and nurses, there has been no research on other medical professions, such as physician assistants, medical technicians and administrative staff, who work together as a team in hospitals. In particular, physician assistants have been recruited in most hospitals in Taiwan. They work together with physicians for direct patient care but their stress and burnout situation have not been reported yet.

This study was aimed at an investigation and comparison of the prevalence of job stress and burnout among different medical professions within a hospital setting. Another aim was to explore the associated factors that contribute to burnout across these professions. We hope these findings can facilitate the development of effective strategies of stress reduction programmes in the hospitals.

\section{METHODS}

\section{Participants and study design}

The medical professionals used as the sample in this study were recruited from a regional teaching hospital in Tainan, Taiwan. The five medical professions included in the survey were doctor, nurse, physician assistant, medical technician and administrative staff. After reading the informed consent, all the voluntary participants completed an electronic questionnaire on the Training and Management System of the hospital from the first day of February through the end of March 2012. Finally, 1329 participants finished the questionnaire, and the response rate was $89 \%$.

\section{Questionnaire}

The questionnaire used in the study included sociodemographic information, working conditions, level of burnout and job stress, lifestyle behaviours and medical history. Sociodemographic information included gender, age, educational level and marital status. Working conditions included length of employment in current position, working hours per week, whether or not participants were doing shift work. Lifestyle factors included hours of sleep every night, healthy diet per week ( $\geqq 5$ servings of vegetable and fruits per day), time spent on physical activities per week and smoking status.

\section{Burnout}

The newly developed Copenhagen Burnout Inventory (CBI) by Kristensen et $a l^{15}$ is a more straightforward measurement of burnout in the population of medical professionals as compared to the standard Maslach Burnout Inventory (MBI). ${ }^{16}$ The CBI assesses burnout status using three dimensions: personal burnout, workrelated burnout and client-related burnout.

In this research, the burnout status was assessed by a Chinese version of the Copenhagen Burnout Inventory (C-CBI), which was constructed based on the CBI with good validity and reliability. ${ }^{17} 18$ The C-CBI consists of 16 items: personal burnout accounts for five items, workrelated burnout accounts for five items, and client-related burnout accounts for six items. All items used a Likert-type, five-response category scale. The responses were rescaled to a 0-100 metric. In this survey, the questionnaire had a Cronbach's $\alpha$ coefficient for each dimension of $0.93,0.93$ and 0.92 , respectively. A high burnout score $\geqq 50$ indicates high burnout in the analysis.

\section{Job stress}

We also included the qualified Chinese version of the Job Content Questionnaire (C-JCQ), which was derived from Karasek's demand-control-support model to measure job strain, because this model has been considered one of the dominant tools for measuring job stress. ${ }^{19}$ This model was highly associated with hypertension and the intima-media thickness of the carotid artery ${ }^{20-22}$ and was also well correlated to coronary heart disease in a recent published paper. $^{23}$ A total of 25 items are included, with psychological work demands, 9 items; job control, 8 items; supervisor support, 4 items and coworker support, 4 items. Each item of the inventory was measured on a four-point scale (strongly agree to strongly disagree). A subscale of 'overcommitment' specified by Siegrist et $a l^{24}{ }^{25}$ was also included in our questionnaire. The measurement of overcommitment was based on five items on a five-point Likert scale. Cronbach's $\alpha$ coefficients for the dimension of demand, control, supports and overcommitment in this study were $0.47,0.64,0.87$ and 0.83 , respectively.

\section{Statistical analysis}

Demographic data including gender, age, level of education and marital status, as well as work situations such as position, work hours and work shifts, were recorded as numbers and percentages. One-way analysis of variance was used for the analysis of burnout according to the sociodemographic information, profession, work conditions and level of job strain. Correlation analysis was performed to analyse the relationships among independent variables influencing burnout in order to avoid a multicollinearity problem in the multiple regression analysis (not shown in the result). Multiple regression analysis for different models was performed to identify the factors influencing work-related burnout. All calculations were performed using a software SPSS V.17, with the level of significance set at $\mathrm{p}<0.05$. 


\section{RESULTS}

\section{Characteristics of the participants}

The sociodemographic factors, job characteristics and medical profession information are summarised in table 1. The participants were female dominant $(82.8 \%)$. The majority age group was $30-39$ years, and the mean age across participants was 38.3 years. Most medical professionals were married $(62.5 \%)$ and graduated with a 4-year university degree $(83.1 \%)$ at the time of study. More than half of the participants work overtime routinely, and nearly half of the medical professions worked in shifts.

\section{Factors associated with burnout}

Table 2 shows that women had significantly higher burnout scores than men in personal and work-related burnout but not in the client-related burnout. Older staff had significantly lower burnout scores than younger staff on the three dimensions of burnout. Participants who graduated from a college had lower burnout scores than those who graduated from high school or graduate school. Among medical professions, nurses and physician assistants had the top two highest burnout scores among the three dimensions. With regard to job strain, active and high strain perception was characterised by a significantly higher degree of burnout than was the case for those who perceived their level of strain as passive or low. Frequency of overcommitment was positively correlated with the score of all three dimensions of burnout.

\begin{tabular}{|c|c|c|}
\hline Factors & $\mathbf{N}$ & Per cent \\
\hline \multicolumn{3}{|l|}{ Gender } \\
\hline Male & 228 & 17.2 \\
\hline Female & 1101 & 82.8 \\
\hline \multicolumn{3}{|l|}{ Age (years) } \\
\hline$<30$ & 209 & 15.7 \\
\hline $30-39$ & 602 & 45.3 \\
\hline $40-49$ & 378 & 28.4 \\
\hline$\geqq 50$ & 139 & 10.5 \\
\hline \multicolumn{3}{|l|}{ Education } \\
\hline High school & 135 & 10.2 \\
\hline College/university & 1105 & 83.1 \\
\hline Graduate school & 89 & 6.7 \\
\hline \multicolumn{3}{|l|}{ Marital status } \\
\hline Single & 499 & 37.5 \\
\hline Married & 830 & 62.5 \\
\hline \multicolumn{3}{|l|}{ Profession } \\
\hline Physician & 101 & 7.6 \\
\hline Physician assistant & 68 & 5.1 \\
\hline Nurse & 570 & 42.9 \\
\hline Medical technician & 216 & 16.3 \\
\hline Administrative staff & 374 & 28.1 \\
\hline \multicolumn{3}{|l|}{ Work hours (weekly) } \\
\hline Normal ( $\leqq 44$ h) & 472 & 35.5 \\
\hline Overtime (>44 h) & 857 & 64.5 \\
\hline \multicolumn{3}{|l|}{ Work shifts } \\
\hline No & 684 & 51.5 \\
\hline Yes & 645 & 48.5 \\
\hline
\end{tabular}

Finally, lower social support was negatively correlated with the three burnout scores.

\section{Predictors of work-related burnout}

The results of multiple regression analysis of predicting variables to work-related burnout are shown in table 3 . Model 1 demonstrated that gender and age, but not level of education or marital status, had a significant correlation to burnout. In model 2, working overtime and working in shifts had additional effects with regard to burnout. When allocating medical professions to model 3 , it was indicated that nurses and physician assistants had significantly higher burnout than the other three medical professions, and the gender effects were thus insignificant. In the full model (model 4), those who perceived high or active job strain had a much higher prevalence of burnout than those with low and passive strain. Professionals who sometimes/often overcommit were demonstrated to have higher levels of burnout than those who indicated that they never or seldom overcommit. Finally, professionals with low social support had a significantly higher burnout. Among these factors, job strain, overcommitment and social support demonstrated remarkable association with work-related burnout, which could explain $30.1 \%$ of variance in burnout.

\section{Burnout and job stressors among medical professions}

In table 4, nurses are shown to have the highest prevalence of high burnout among medical professions. The next highest were the physician assistants, with a severity of burnout very similar to that of nurses. However, physicians, medical technicians and administrative staff had similar burnout conditions on the personal and workrelated dimensions, but physicians had more severity of client-related burnout than the other professions, with the exception of nurses.

Compared with the other professions, nurses as a group had the characteristics of youngest age, were mostly women $(99.5 \%)$, were mostly engaged in shift work $(74 \%)$, as well as had the highest percentage (27.9\%) perceiving high strain. Physician assistants as a group had the highest overcommitment $(44.1 \%)$ and lowest support $(60.3 \%)$. They were also characterised as having a high percentage of women (91.2\%), long work hours and the second highest percentage (27.2\%) experiencing high strain. Physicians as a group had the features of being the oldest on average and had the highest percentage of longer work hours $(48.5 \%)$, but very few perceived high strain $(2 \%)$. Medical technicians and administrative staff had a similar percentage of female members, social support, longer work hours and those testing for high strain $(14.4 \%, 14.7 \%)$.

\section{DISCUSSION}

This study investigated the prevalence of burnout among different medical professions and examined the associated 
Table 2 Analysis of burnout score according to sociodemographic, profession and job stressors $(n=1329)$

\begin{tabular}{|c|c|c|c|c|c|c|}
\hline \multirow[b]{2}{*}{ Variable } & \multicolumn{2}{|c|}{ Personal burnout } & \multicolumn{2}{|c|}{ Work-related burnout } & \multicolumn{2}{|c|}{ Client-related burnout } \\
\hline & Mean \pm SD & p Value & Mean \pm SD & p Value & Mean $\pm S D$ & p Value \\
\hline Gender & & $<0.001$ & & $<0.001$ & & 0.296 \\
\hline Male & $43.2 \pm 20.0$ & & $40.9 \pm 20.0$ & & $37.4 \pm 18.9$ & \\
\hline Female & $53.9 \pm 21.4$ & & $49.4 \pm 21.1$ & & $38.8 \pm 18.9$ & \\
\hline Age (years) & & $<0.001$ & & $<0.001$ & & $<0.001$ \\
\hline$<30$ & $56.7 \pm 22.9$ & & $55.0 \pm 23.0$ & & $42.8 \pm 20.1$ & \\
\hline 30-39 & $54.7 \pm 21.2$ & & $49.9 \pm 20.6$ & & $39.4 \pm 18.8$ & \\
\hline $40-49$ & $48.7 \pm 21.5$ & & $44.7 \pm 20.5$ & & $37.3 \pm 17.8$ & \\
\hline$\geqq 50$ & $42.8 \pm 17.0$ & & $37.6 \pm 17.4$ & & $31.8 \pm 18.1$ & \\
\hline Educational level & & $<0.05$ & & $<0.05$ & & 0.353 \\
\hline High school & $55.7 \pm 21.9$ & & $50.5 \pm 21.9$ & & $40.8 \pm 18.9$ & \\
\hline College/university & $51.0 \pm 21.6$ & & $47.3 \pm 21.1$ & & $38.3 \pm 18.8$ & \\
\hline Graduate school & $58.0 \pm 21.2$ & & $52.2 \pm 21.9$ & & $38.6 \pm 19.3$ & \\
\hline Marital status & & 0.299 & & 0.078 & & $<0.05$ \\
\hline Single & $52.8 \pm 21.9$ & & $49.3 \pm 21.6$ & & $39.9 \pm 18.9$ & \\
\hline Married & $51.6 \pm 21.3$ & & $47.2 \pm 20.9$ & & $37.7 \pm 18.8$ & \\
\hline Profession & & $<0.001$ & & $<0.001$ & & $<0.001$ \\
\hline Physician & $43.3 \pm 18.6$ & & $41.5 \pm 19.0$ & & $38.6 \pm 16.7$ & \\
\hline Physician assistant & $58.7 \pm 20.7$ & & $54.7 \pm 21.9$ & & $41.1 \pm 17.7$ & \\
\hline Nurse & $60.1 \pm 20.8$ & & $55.8 \pm 21.1$ & & $42.9 \pm 19.1$ & \\
\hline Medical technician & $43.9 \pm 19.1$ & & $39.5 \pm 17.4$ & & $32.9 \pm 18.4$ & \\
\hline Administrative staff & $45.5 \pm 20.2$ & & $41.5 \pm 19.2$ & & $34.6 \pm 17.9$ & \\
\hline Work hours (weekly) & & $<0.001$ & & $<0.001$ & & $<0.001$ \\
\hline Normal (@44 h) & $49.6 \pm 20.7$ & & $40.1 \pm 19.0$ & & $34.3 \pm 18.2$ & \\
\hline Overtime (>44 h) & $60.4 \pm 22.3$ & & $52.3 \pm 21.1$ & & $40.9 \pm 18.8$ & \\
\hline Work shifts & & $<0.001$ & & $<0.001$ & & $<0.001$ \\
\hline Fixed shift & $48.4 \pm 20.8$ & & $44.3 \pm 20.2$ & & $36.7 \pm 18.6$ & \\
\hline In shift & $55.8 \pm 21.7$ & & $51.9 \pm 21.6$ & & $40.5 \pm 18.9$ & \\
\hline Job strain & & $<0.001$ & & $<0.001$ & & $<0.001$ \\
\hline Low & $42.7 \pm 18.7$ & & $38.6 \pm 18.5$ & & $34.5 \pm 16.9$ & \\
\hline Passive & $46.3 \pm 18.1$ & & $42.5 \pm 16.9$ & & $34.3 \pm 16.7$ & \\
\hline Active & $61.9 \pm 20.6$ & & $55.6 \pm 19.6$ & & $42.3 \pm 19.3$ & \\
\hline High & $67.9 \pm 19.3$ & & $65.4 \pm 20.1$ & & $48.7 \pm 20.2$ & \\
\hline Overcommitment & & $<0.001$ & & $<0.001$ & & $<0.001$ \\
\hline Never/seldom (0-25) & $33.8 \pm 17.4$ & & $29.9 \pm 18.2$ & & $25.7 \pm 15.5$ & \\
\hline Sometimes $(26-50)$ & $46.1 \pm 17.9$ & & $42.3 \pm 17.0$ & & $35.6 \pm 16.3$ & \\
\hline Often/always $(\geqq 51)$ & $65.8 \pm 19.8$ & & $61.4 \pm 20.2$ & & $46.5 \pm 19.9$ & \\
\hline Social support & & $<0.001$ & & $<0.001$ & & $<0.010$ \\
\hline Low (<24) & $55.9 \pm 21.5$ & & $53.0 \pm 21.6$ & & $40.4 \pm 20.1$ & \\
\hline High $(\geqq 24)$ & $49.6 \pm 21.2$ & & $45.0 \pm 20.4$ & & $37.5 \pm 18.1$ & \\
\hline
\end{tabular}

factors related to burnout. Our findings showed that being young, working overtime, being a nurse or physician assistant, engaged in a job with high strain, frequent overcommitment and low social support were associated with high burnout. Above all, the three variables of job strain, overcommitment and lack of social support explained most of the variance related to burnout.

To our knowledge, this is the first report to compare most of the medical professions in a hospital setting. The advantages of large sample size and high response rate also strengthen the power of this study. The results indicated that nurses have the highest burnout scores as compared to the other medical professions, which is consistent with a previous report. ${ }^{26}$ The mean burnout score and percentage of high burnout in nurses $(60.1 \%$ and $73.2 \%$ in this study) were shown to be much higher than in other studies using similar instruments. ${ }^{8} 15162728$ The primary cause of stress for hospital staff came from the preparation of hospital accreditation, and the second cause of stress was the threat of medical malpractice lawsuits. ${ }^{26}$ This reason may partially explain the high burnout in Taiwan's medical professionals. In addition, Heinen $e t a l^{29}$ reported that high burnout is consistently associated with the nurse's intention to leave the profession. This seems to be a vicious cycle. Therefore, Taiwan's nurses have a high workload and lack of adequate staffing for periods of times which they describe as being 'trapped in hell'. ${ }^{30}$

The second group most susceptible to burnout is physician assistants (also called clinical nurse specialists after 
Table 3 Multiple regression analysis of factors associated with work-related burnout $(n=1329)$

\begin{tabular}{|c|c|c|c|c|}
\hline Variables & $\begin{array}{l}\text { Model } 1 \\
\beta(95 \% \text { Cl) }\end{array}$ & $\begin{array}{l}\text { Model } 2 \\
\beta(95 \% \mathrm{Cl})\end{array}$ & $\begin{array}{l}\text { Model } 3 \\
\beta(95 \% \mathrm{Cl})\end{array}$ & $\begin{array}{l}\text { Model } 4 \\
\text { B (95\% Cl) }\end{array}$ \\
\hline \multicolumn{5}{|l|}{ Gender } \\
\hline Male & 0 & 0 & 0 & 0 \\
\hline Female & $5.2(2.1 \text { to } 8.2)^{\star \star}$ & $5.4(2.4 \text { to } 8.4)^{\star \star \star}$ & $0.6(-2.9$ to 4.0$)$ & $0.849(-1.9$ to 3.6$)$ \\
\hline \multicolumn{5}{|l|}{ Age (years) } \\
\hline$\geqq 50$ & 0 & 0 & 0 & 0 \\
\hline$\overline{40}-49$ & $6.1(2.0 \text { to } 10.1)^{\star \star}$ & $6.1(2.1 \text { to } 10.0)^{\star \star}$ & $4.6(0.7 \text { to } 8.6)^{*}$ & $3.8(0.7 \text { to } 7.0)^{*}$ \\
\hline 30-39 & $10.3(6.4 \text { to } 14.2)^{\star \star \star}$ & $8.8(4.9 \text { to } 12.6)^{\star \star \star}$ & $6.1(2.2 \text { to } 10.0)^{\star \star}$ & $6.5(3.4 \text { to } 9.7)^{\star \star \star}$ \\
\hline$<30$ & $15.3(10.7 \text { to } 19.9)^{\star \star \star}$ & $12.6(8.1 \text { to } 17.2)^{\star * *}$ & $9.1(4.5 \text { to } 13.7)^{\star \star *}$ & $10.3(6.5 \text { to } 13.9)^{\star \star \star}$ \\
\hline \multicolumn{5}{|l|}{ Educational level } \\
\hline High school & 0 & 0 & 0 & 0 \\
\hline College/university & $-2.0(-5.8$ to 1.7$)$ & $-2.9(-6.5$ to 0.7$)$ & $-1.7(-5.2$ to 1.9$)$ & $-0.8(-3.6$ to 2.1$)$ \\
\hline Graduate school & $2.2(-3.3$ to 7.7$)$ & $0.7(-4.7$ to 6.1$)$ & $1.3(-3.9$ to 6.7$)$ & $0.4(-3.8$ to 4.6$)$ \\
\hline \multicolumn{5}{|l|}{ Marital status } \\
\hline Married & 0 & 0 & 0 & 0 \\
\hline Single & $0.8(-1.6$ to 3.1$)$ & $1.0(-1.2$ to 3.3$)$ & $1.4(-0.8$ to 3.6$)$ & $0.2(-1.6$ to 1.9$)$ \\
\hline \multicolumn{5}{|l|}{ Work hours (weekly) } \\
\hline Normal ( $\leqq 44$ h) & & 0 & 0 & 0 \\
\hline Overtime (>44 h) & & $9.7(7.1 \text { to } 12.3)^{\star * \star}$ & $7.8(5.2 \text { to } 10.5)^{\star \star \star}$ & $2.9(0.7 \text { to } 5.1)^{\star \star}$ \\
\hline \multicolumn{5}{|l|}{ Work shift } \\
\hline Fixed shift & & 0 & 0 & 0 \\
\hline In shift & & $4.8(2.6 \text { to } 7.1)^{\star \star \star}$ & $1.9(-0.5$ to 4.3$)$ & $0.7(-1.2$ to 2.7$)$ \\
\hline \multicolumn{5}{|l|}{ Profession } \\
\hline Medical technician & & & 0 & 0 \\
\hline Administrative staff & & & $3.7(0.3 \text { to } 7.0)^{*}$ & $1.9(-0.7$ to 4.6$)$ \\
\hline Physician & & & $1.4(-3.8$ to 6.7$)$ & $4.1(-0.1$ to 8.3$)$ \\
\hline Physician assistant & & & $12.7(7.3 \text { to } 18.2)^{\star \star \star}$ & $6.6(2.2 \text { to } 11.0)^{\star *}$ \\
\hline Nurse & & & $12.9(9.6 \text { to } 16.3)^{\star \star \star}$ & $7.7(4.9 \text { to } 10.4)^{\star \star \star}$ \\
\hline \multicolumn{5}{|l|}{ Job strain } \\
\hline Low & & & & 0 \\
\hline Passive & & & & $1.6(-0.6$ to 3.9$)$ \\
\hline Active & & & & $7.5(4.8 \text { to } 10.1)^{\star \star \star}$ \\
\hline High & & & & $16.1(13.4 \text { to } 18.7)^{\star \star \star}$ \\
\hline \multicolumn{5}{|l|}{ Overcommitment } \\
\hline Never/seldom (0-25) & & & & 0 \\
\hline Sometimes $(26-50)$ & & & & $10.5(7.6 \text { to } 13.4)^{\star \star \star}$ \\
\hline Often/always $(\geqq 51)$ & & & & $24.9(21.8 \text { to } 28.0)^{\star \star \star}$ \\
\hline \multicolumn{5}{|l|}{ Social support } \\
\hline High $(\geqq 24)$ & & & & 0 \\
\hline Low $(<24)$ & & & & $6.4(4.5 \text { to } 8.2)^{\star \star \star}$ \\
\hline $\mathrm{R}^{2}$ & 0.064 & 0.116 & 0.160 & 0.461 \\
\hline Adjust $\mathrm{R}^{2}$ & 0.059 & 0.110 & 0.152 & 0.453 \\
\hline
\end{tabular}

${ }^{*} p<0.05,{ }^{* *} p<0.01,{ }^{* * *} p<0.001$.

Model 1 adjusted for gender, age, education and marriage.

Model 2 adjusted for variables of model 1 with additional adjustment for work hours and work shift.

Model 3 adjusted for variables of model 2 and profession.

Model 4 adjusted for variables of model 3 with additional adjustment for job strain, overcommitment and social support.

2000). ${ }^{31}$ Their burnout scores and prevalence of high burnout were very close to that of nurses. The possible reason for this is that physician assistants have been recruited due to a shortage of resident physicians in most of Taiwan's hospitals since $1994 .^{31}$ Most of them had graduated from college or above, had 2-4 years of clinical experience and had received a half-year of additional training. Their routine work is to assist attending physicians to care for patients and complete medical records. Most of the time, physician assistants may face emergent and critical conditions of patients and make immediate responses. This is really a big challenge in their work. In our analysis, physician assistants had a higher percentage of related factors towards burnout than physicians had, which included being female, of younger age, experiencing high strain, overcommitment and low social support.

The unanticipated result in this study is that the burnout scores of physicians were very close to those of medical technicians and administrative staff. The mean 
Table 4 Distribution of age, gender, job stressors and burnout among medical professions ( $N=1329)$

\begin{tabular}{|c|c|c|c|c|c|c|}
\hline Variables & $\begin{array}{l}\text { Physician } \\
\mathrm{n}=101\end{array}$ & $\begin{array}{l}\text { Physician assistant } \\
\mathrm{n}=68\end{array}$ & $\begin{array}{l}\text { Nurse } \\
n=570\end{array}$ & $\begin{array}{l}\text { Medical technician } \\
\mathrm{n}=216\end{array}$ & $\begin{array}{l}\text { Administrators } \\
\mathrm{n}=374\end{array}$ & p Value \\
\hline \multicolumn{7}{|l|}{ High burnout (\%) } \\
\hline Personal burnout $(\geqq 50)$ & 41.6 & 69.1 & 73.2 & 42.6 & 45.5 & $<0.001$ \\
\hline Work-related burnout $(\geqq 50)$ & 38.6 & 61.8 & 66.0 & 31.9 & 36.1 & $<0.001$ \\
\hline Client-related burnout $(\geqq 50)$ & 36.6 & 33.8 & 43.3 & 22.2 & 26.2 & $<0.001$ \\
\hline \multicolumn{7}{|c|}{ Job stressor } \\
\hline High strain (\%) & 2.0 & 27.2 & 27.9 & 14.4 & 14.7 & $<0.001$ \\
\hline Overcommitment (often, \%) & 30.7 & 44.1 & 43.7 & 24.1 & 31.8 & $<0.001$ \\
\hline Social support (low, \%) & 28.7 & 60.3 & 37.0 & 37.0 & 38.2 & $<0.001$ \\
\hline Work overtime (>44 h, \%) & 48.5 & 44.1 & 29.1 & 9.7 & 9.6 & $<0.001$ \\
\hline Work shift (in shift, \%) & 46.1 & 29.4 & 74.0 & 38.0 & 21.1 & $<0.001$ \\
\hline Age (mean+SD) & $45.3 \pm 7.5$ & $38.4 \pm 4.8$ & $33.9 \pm 6.5$ & $37.9 \pm 8.1$ & $42.3 \pm 8.6$ & $<0.001$ \\
\hline Gender (female, \%) & 16.8 & 91.2 & 99.5 & 75.0 & 78.3 & $<0.001$ \\
\hline
\end{tabular}

burnout score and prevalence of high burnout in physicians in this study were $43.3 \%$ and $41.6 \%$. These data are very close to scores from Mongolian physicians but higher than those found in Danish physicians, Australian dentists and other occupations in Taiwan. $^{1516263233}$

Although this study has some strengths, there are still several limitations that need to be addressed. First, our participants were from a single regional hospital; therefore, it is not possible to generalise the conclusions for medical professions across the whole of Taiwan's hospitals. Therefore, the design for further study can expand to include more institutions. Second, stressful life events and work-family conflicts, which may affect the outcome of burnout, as found in other studies, were not examined in this research. Finally, this study was conducted with a cross-sectional design; therefore, the limitation of weak causal inference is inherent. A longitudinal follow-up of the employee's stressor and burnout condition is necessary to improve these relationships in the future.

We conclude that nurses and physician assistants suffered from the highest burnout as compared to physicians, administrative staff and medical technicians in the hospital setting selected for this study. Also, a job with high strain, frequent feelings of overcommitment as well as working without superintendent and coworker support resulted in the highest percentages of burnout. The above findings may facilitate the development of feasible and rational strategies to design and implement stress reduction programmes in hospitals.

For example, the results showed burnout to be higher in younger individuals, as well as in those who work overtime, perceive high strain, and in those who frequently overcommit or receive low social support. Therefore, we suggest that the target group of stress reduction programmes should focus on younger professionals first and the intervention strategies must cover individual/ group and environmental levels. The former includes communication skill training, stress and time management and senior-junior support groups, etc. The latter includes a suitable worksheet, reasonable welfare, a healthy working environment, etc.

Contributors All authors participated in the interpretation of data, wrote and critically reviewed the paper. L-PC designed and conducted the study and also wrote the draft. C-YL was the statistical consultant and revised and interpreted the tables. SCH was the advisor for the whole study and completed the manuscript.

Funding This study was financially supported by the Sin-Lau Christian Hospital, Tainan, Taiwan, grant number: SLH101-16.

Competing interests None.

Patient consent Obtained.

Ethics approval The study was approved by the Ethics Review Board of Sin-Lau Hospital.

Provenance and peer review Not commissioned; externally peer reviewed.

Data sharing statement No additional data are available.

Open Access This is an Open Access article distributed in accordance with the Creative Commons Attribution Non Commercial (CC BY-NC 3.0) license, which permits others to distribute, remix, adapt, build upon this work noncommercially, and license their derivative works on different terms, provided the original work is properly cited and the use is non-commercial. See: http:// creativecommons.org/licenses/by-nc/3.0/

\section{REFERENCES}

1. Maslach C, Schaufeli WB. Historical and conceptual development of burnout. Prof Burnout 1993:1-16.

2. Collings JA, Murray PJ. Predictors of stress amongst social workers: an empirical study. Br J Soc Work 1996;26:375-87.

3. Freudenberger HJ. Staff burnout. J Soc Issues 1974;30:159-65.

4. Maslach C, Schaufeli WB, Leiter MP. Job burnout. Annu Rev Psychol 2001;52:397-422.

5. Bakker AB, Demerouti E. The job demands-resources model: state of the art. J Manager Psychol 2007;22:309-28.

6. West CP, Huschka MM, Novotny PJ, et al. Association of perceived medical errors with resident distress and empathy. JAMA 2006;296:1071-8.

7. Williams ES, Manwell LB, Konrad TR, et al. The relationship of organizational culture, stress, satisfaction, and burnout with physician-reported error and suboptimal patient care: results from the MEMO study. Health Care Manage Rev 2007;32:203-12.

8. Klein J, Grosse Frie K, Blum K, et al. Burnout and perceived quality of care among German clinicians in surgery. Int $J$ Qual Health Care 2010;22:525-30.

9. Gray-Toft P, Anderson JG. Stress among hospital nursing staff: its causes and effects. Soc Sci Med A 1981;15:639-47. 
10. Prins JT, Gazendam-Donofrio SM, Tubben BJ, et al. Burnout in medical residents: a review. Med Educ 2007;41:788-800.

11. Balch CM, Freischlag JA, Shanafelt TD. Stress and burnout among surgeons: understanding and managing the syndrome and avoiding the adverse consequences. Arch Surg 2009;144:371

12. Lue $\mathrm{BH}$, Chen $\mathrm{HJ}$, Wang $\mathrm{CW}$, et al. Stress, personal characteristics and burnout among first postgraduate year residents: a nationwide study in Taiwan. Med Teach 2010;32:400-7.

13. Siu C, Yuen SK, Cheung A. Burnout among public doctors in Hong Kong: cross-sectional survey. Hong Kong Med J 2012;18:186-92.

14. Shanafelt TD, Sloan JA, Habermann TM. The well-being of physicians. Am J Med 2003;114:513-19.

15. Kristensen TS, Borritz M, Villadsen $\mathrm{E}$, et al. The Copenhagen Burnout Inventory: a new tool for the assessment of burnout. Work Stress 2005;19:192-207.

16. Winwood PC, Winefield $\mathrm{AH}$. Comparing two measures of burnout among dentists in Australia. Int J Stress Manage 2004;11:282-9.

17. Yeh WY, Cheng Y, Chen CJ, et al. Psychometric properties of the Chinese version of Copenhagen burnout inventory among employees in two companies in Taiwan. Int $J$ Behav Med 2007;14:126-33.

18. Yeh WY, Cheng Y, Chen MJ, et al. Development and validation of an occupational burnout inventory. Taiwan J Public Health 2008;27:349-64.

19. Cheng Y, Luh WM, Guo YL. Reliability and validity of the Chinese Version of the Job Content Questionnaire in Taiwanese Workers. Int J Behav Med 2003;10:15-30.

20. Tsutsumi A, Kayaba K, Tsutsumi K, et al. Association between job strain and prevalence of hypertension: a cross sectional analysis in a Japanese working population with a wide range of occupations: the Jichi Medical School cohort study. Occup Environ Med 2001;58:367-73.

21. Radi S, Lang T, Lauwers-Cances $\mathrm{V}$, et al. Job constraints and arterial hypertension: different effects in men and women: the IHPAF II case control study. Occup Environ Med 2005;62:711-17.
22. Fujishiro K, Roux AVD, Landsbergis $\mathrm{P}$, et al. Associations of occupation, job control and job demands with intima-media thickness: the Multi-Ethnic Study of Atherosclerosis (MESA). Occup Environ Med 2011;68:319-26.

23. Kivimäki M, Singh-Manoux A, Nyberg S, et al. Job strain and coronary heart disease-authors' reply. Lancet 2013;381:448-9.

24. Siegrist J, Peter R, Junge A, et al. Low status control, high effort at work and ischemic heart disease: prospective evidence from blue-collar men. Soc Sci Med 1990;31:1127-34.

25. Li J, Yang W, Cheng Y, et al. The reliability and validity of the Chinese version of effort-reward imbalance questionnaire among health care workers: a validation study. Int Arch Occup Environ Med 2004;78:198-204

26. Ho HC, Chang SH, Tsao JY, et al. The relationship between job stress and physical-mental health among hospital staff. Chin J Occup Med 2010;17:239-52.

27. Bagaajav A, Myagmarjav S, Nanjid K, et al. Burnout and job stress among Mongolian doctors and nurses. Ind Health 2011;49:582-8.

28. Fuss I, Nübling M, Hasselhorn HM, et al. Working conditions and work-family conflict in German hospital physicians: psychosocial and organisational predictors and consequences. BMC Public Health 2008;8:353-69.

29. Heinen MM, van Achterberg T, Schwendimann R, et al. Nurses' intention to leave their profession: a cross sectional observational study in 10 European countries. Int J Nurs Stud 2013;50:174-84.

30. Lin M. The dark moment of nurses in Taiwan. CNN report 14 April 2012.

31. Chen C. The current issues an advanced nursing practice in Taiwan. Geneva: ICN, 2001

32. Yeh WY, Cheng Y, Chen MJ, et al. Factors associated with workers' burnout and "over-commitment to work": a survey among employees of 36 companies in Taipei city. Taiwan J Public Health 2008;27:463-77.

33. Yeh WY, Cheng $Y$, Chen CJ. Social patterns of pay systems and their associations with psychosocial job characteristics and burnout among paid employees in Taiwan. Soc Sci Med 2009;68:1407-15. 